\title{
Mindful Awareness or Self-Regulation in Eating: an Investigation into the Underlying Dimensions of Mindful Eating
}

\author{
Nóra Román ${ }^{1,2}$ (D) Róbert Urbán ${ }^{2}$ \\ Published online: 27 May 2019 \\ (C) The Author(s) 2019
}

\begin{abstract}
Objectives Mindful eating has been suggested to contribute a healthier relationship to food. However, its conceptualization and operationalization need further investigation. Our aim was to evaluate the psychometric properties of the Hungarian version of the Mindful Eating Questionnaire (MEQ).

Methods A cross-sectional survey study including a sample of Hungarian university students $(N=323)$ was conducted to unveil the construct validity of the MEQ.

Results The results of the confirmatory factor analysis revealed an inadequate fit to the original model. Applying exploratory factor analysis (EFA) confirmed the presence of the original five factors with minor deviations from the original structure. Correlation coefficients between factors ranged from -0.36 to 0.52 . As a further step, principal component analysis of the primary factors uncovered two second-order components, self-regulation, and awareness. A multivariate regression analysis with structural equation modeling revealed that higher levels of self-regulation in eating were positively related to trait mindfulness $(\beta=0.13, p<0.05)$ and negatively related to uncontrolled eating $(\beta=-0.20, p<0.05)$, emotional eating $(\beta=-0.40$, $p<0.05)$, and meditation practice $(\beta=-0.12, p<0.05)$. In turn, awareness was related to lower body mass index $(\beta=-0.20$, $p<0.05)$ and higher levels of emotional eating $(\beta=0.20, p<0.05)$.

Conclusions These results suggest inadequate coherence of the subscales and an unclear locus of mindful eating within the nomological network of related constructs. Our study contributes to the progress in the measurement of mindful eating by highlighting the strengths and weaknesses of the MEQ. The outcome of the construct validation testing implies the need for further exploration of mindful eating.
\end{abstract}

Keywords Measurement $\cdot$ Mindfulness $\cdot$ Eating behavior $\cdot$ Mindful eating questionnaire

Obesity and unhealthy eating behaviors are among the major health risks all over the world (Hruby and $\mathrm{Hu} 2015$ ). Preventing negative impacts of the obesogenic environment requires changing attitudes and awareness of eating behaviors (Elliston et al. 2017; Kremers et al. 2006). Current psychological interventions for weight loss are successful in weight reduction, but their long-term effectiveness for maintaining the

Nóra Román

roman.nora@ppk.elte.hu

1 Doctoral School of Psychology, ELTE Eötvös Loránd University, Izabella utca 46, Budapest H-1064, Hungary

2 Institute of Psychology, ELTE Eötvös Loránd University, Izabella utca 46, Budapest H-1064, Hungary lower body weight is less convincing (Cooper et al. 2010). Therefore, there is a clear need for new approaches to prevent and treat obesity. While robust interventional research is still scarce, studies suggest that mindfulness-based interventions might be able to effectively alter the unhealthy eating habits related to overweight and obesity (O'Reilly et al. 2014).

Mindfulness is a specific approach to "being" that enables individuals to fully experience the present moment as it is by intentionally and consciously directing attention to as many attributes of the moment as possible (Brown et al. 2007). Practicing mindfulness in the food environment can reduce food cravings and the frequency of eating induced by external cues (Alberts et al. 2012; Allirot et al. 2017). By being more mindful of the present moment, the sensations of hunger and satiety can be brought back into the focus of conscious experience. Thus, people might become less influenced by external 
stimuli or internal feelings that might lead to decreased food intake (Caldwell et al. 2012). Mindfulness also seems to lead to significant reductions in body mass index (BMI) with moderate effect sizes (Carrière et al. 2018). It has a positive impact on vegetable and fruit consumption and is associated with increased self-efficacy regarding healthy eating (Gilbert and Waltz 2010; Niemeier et al. 2012; Roberts and Danoff-Burg 2010; Tapper et al. 2009). Additionally, mindfulness can be described as a form of self-regulation that creates space between stimulus and reaction and provides an opportunity for conscious intervention (Brown and Ryan 2003; Brown et al. 2007). When examining the connection between impulsiveness and mindfulness in the food environment and in obesity, Hendrickson and Rasmussen $(2013,2017)$ found that participants with higher BMI tend to make more impulsive decisions regarding eating, but after a short mindfulness training, they start making less impulsive food choices and can delay the onset of eating. Significant negative associations were reported not only in relation to impulsivity but also emotional and uncontrolled eating using correlational and interventional study designs (e.g., Jordan et al. 2014).

In parallel with the studies conducted on the associations of mindfulness and health behaviors, the notion of mindful eating was coined. Since there is no universally accepted definition of mindful eating, only its most commonly described features can be presented here. These include the recognition of internal and external cues of hunger and satiety that have an impact on food choices and portion sizes; focusing attention and awareness on the process of eating including the taste, smell, texture and sight of the meal; slowing the rate of eating; encouraging a non-judgmental acceptance of food, its environment, and one's physical and emotional reactions to them; minimizing distractions while eating; and being aware of the consequences of mindless eating (Mathieu 2009; Monroe 2015). Indeed, research reveals that practicing mindful eating specifically enables individuals to recognize why they eat, facilitates noticing hunger and satiety cues and giving appropriate reactions to them. It also makes it easier to notice if external and internal stimuli, such as the sight of an advertisement, feeling bored or anxious are misinterpreted as hunger (Allirot et al. 2017; Hart 2014; Papies et al. 2015). Mindful eating interventions were shown to be effective in treating emotional eating, with medium to large effect sizes (O’Reilly et al. 2014; Pidgeon et al. 2013). Evidence also indicates that people who are overweight $(\mathrm{BMI} \geq 25)$ or obese (BMI $\geq 30$ ) exhibit lower levels of mindfulness and mindful eating than those in the normal weight range (BMI 18.5-24.9) using the World Health Organization (WHO) BMI classification (Camilleri et al. 2015; Moor et al. 2013; WHO 2018).

The Mindful Eating Questionnaire (MEQ) is among the first and most widely used psychometric scales in the English language to measure five dimensions of mindful eating: Disinhibition, Awareness, External Cues, Emotional
Response, and Distraction (Framson et al. 2009). Framson et al. (2009) defined mindful eating as "... a non-judgmental awareness of physical and emotional sensations while eating or in a food-related environment" $(2009$, p. 1440$)$, which also delineates the features of mindful eating included in their survey. In their view, Disinhibition refers to the inability to stop eating even after being full (e.g., "When I'm eating one of my favorite foods, I don't recognize when I've had enough"); Awareness is paying conscious attention to the effect of food on feelings and the physical senses (e.g., "Before I eat I take a moment to appreciate the colors and smells of my food"); the External Cues subscale contains items describing situations when eating behavior is elicited by relevant cues of the environment (e.g., "I notice when I'm eating from a dish of candy just because it's there"); statements in the Emotional Response factor include eating responses induced by negative emotional states (e.g., "When I'm sad I eat to feel better"); and Distraction is immersion in thoughts emerging while eating (e.g., "My thoughts tend to wander while I am eating"). By including these subscales, the authors suggest that mindful eating can be characterized by awareness, the lack of emotional and external eating, and the lack of disinhibition and distraction while eating. Higher scores represent more mindful attitudes toward eating in the case of each subscale, regardless of their designations. Framson et al. (2009) reported a significant inverse relationship between BMI and the scores attained on the total scale and each of the subscales.

Since its construction, the MEQ has undergone some psychometric examination, although only in a few different populations. In the Iranian version, all five of the original subscales were identified (Abbaspoor et al. 2018). The BMI levels of the Iranian respondents showed no association with the MEQ subscales except for awareness. The Italian adaptation resulted in a shorter item pool from which two factors emerged, namely awareness and recognition (Clementi et al. 2017). In this Italian sample, the questionnaire differentiated between male meditators and nonmeditators, with meditators scoring higher on both subscales. No difference was found on the awareness subscale between female meditators and nonmeditators, however. In the same study, normal weight participants scored slightly higher on the subscales compared with overweight and obese individuals. A very similar twofactor structure was found testing an altered version of the MEQ measuring mindful eating in children - awareness and mindless eating (Hart et al. 2018). As part of testing the construct validity of mindful eating, Clementi et al. (2017) detected small to moderate positive associations with mindfulness using the Freiburg mindfulness inventory (FMI) (Walach et al. 2006). Similarly, on a sample of pregnant women, Apolzan et al. (2016) observed positive correlations of various degrees ( $r$ ranging from 0.01 to 0.64 ) between five subscales of the MEQ and the mindful awareness and attention scale (MAAS) (Brown and Ryan 2003). Further examinations employing 
measures of emotional eating, food craving, cognitive restraint, disinhibition, and hunger supported the construct validity of mindful eating measured with the MEQ.

Although there is an increasing lay and scientific interest in the construct of mindfulness in Hungary, no instrument has been adapted in Hungarian to measure mindful eating. Nevertheless, cultivating and measuring healthy eating behaviors needs to be of special importance in Hungary because it is the fourth country with most obese in the Organization for Economic Co-operation and Development (OECD and the European Union 2014). Furthermore, there is also a need for a measure of mindful eating that can be included in further explorative research and intervention studies in the Hungarian population. Testing the construct validity of mindful eating in different languages and cultural contexts can also contribute to the understanding of both the construct and its operationalization. Thus, drawing upon the existing research, the present study aimed to examine the factor structure of the Hungarian version of the MEQ and to test the robustness of the construct validity of mindful eating by exploring its relationship with the psychological constructs of mindfulness, impulsiveness, and emotional, restrained, and uncontrolled eating along with BMI and the presence or lack of meditation practice.

\section{Method}

\section{Participants}

A convenience sample of Hungarian university students was recruited at the Faculty of Education and Psychology of Eötvös Loránd University (ELTE) in Budapest, Hungary. To comply with the inclusion criteria, participants had to be 18 years or older and actively enrolled students at the university. Anyone matching these criteria could participate in the study. This cross-sectional survey study included 323 students. Sample characteristics are shown in Table 1.

\section{Procedure}

The questionnaire adaptation process was guided by the suggestions of the International Test Commission (Gregoire 2018) and Borsa et al. (2012). To construct the Hungarian version of the MEQ, the original questionnaire was first translated to Hungarian by the authors. After reaching an agreement on the first Hungarian version of the measure, the backtranslation to English was done by an English-Hungarian bilingual individual. Then, to resolve the discrepancies between the original and back-translated English versions of the questionnaire and to reach a semantically more precise Hungarian translation of the problematic items (statements including English terms without straightforward Hungarian equivalents, such as "subtle", "sluggish" or the meaning of "appreciate" in some cases), a professional translator was involved in the adaptation process. This version was then tested for the clarity and intelligibility of items by lay individuals and trained psychologists, who only suggested minor modifications that were implemented in the final version of the survey.

Most of the participants $(N=279)$ completed the paperand-pencil format of the questionnaires. Forty-four individuals, who were contacted by e-mail, completed the survey online. In both cases, informed consent was collected prior to filling out the questionnaires, and anonymity was assured. The Ethical Committee of ELTE approved the study protocol.

\section{Measures}

The MEQ (Framson et al. 2009) contains 28 items. Respondents mark their answers on a 4-point Likert scale to indicate to what degree they relate to each of the statements (ranging from $1=$ never/rarely to $4=$ usually/always). Items are grouped into five factors: Disinhibition, Awareness, External Cues, Emotional Response, and Distraction.

The Mindful Awareness and Attention scale (MAAS) is a 15-item, single-factor tool developed by Brown and Ryan (2003) to measure mindfulness as a personality trait. Respondents provide their answers using a 6-point Likert-type scale (ranging from $1=$ almost always to $6=$ almost never). Simor et al. (2013) investigated the psychometric properties of the Hungarian version of the MAAS, reporting adequate reliability indices (Cronbach's $\alpha=0.78$, test-retest reliability $r=0.71, p<0.001)$. In the current study, the internal consistency of the scale was adequate (Cronbach's $\alpha=0.78$ ).

The Three-Factor Eating Questionnaire (TFEQ-R21) maps different behavioral and cognitive specificities in relation to eating and is mainly used among overweight and obese individuals. Its 21 items contribute to the measurement of three factors: Uncontrolled Eating (UE), Cognitive Restraint (CR) and Emotional Eating (EE). The Hungarian adaptation of this questionnaire was validated by Czeglédi and Urbán (2010). The original factor structure was confirmed on a Hungarian sample. For items 1-20, participants give their answers on a 4point Likert-type scale. For the last item, responses are given on an 8-point scale. The internal consistency of the subscales was adequate in the present sample (Cronbach's $\alpha=.82, .88$, and 0.92 , respectively).

The Barratt Impulsiveness Scale (BIS-11) is a 30-item scale measuring Attentional, Motor and Nonplanning Impulsiveness on a 4-point Likert-type scale (ranging from $1=$ never to $4=$ almost always/always; Patton et al. 1995 ; Stanford et al. 2009). The Hungarian version of this questionnaire was validated by Kapitány-Fövény et al. (2018). In this study, the overall impulsiveness score was used. The scale internal consistency was adequate (Cronbach's $\alpha=.81$ ). 
Table 1 Sample characteristics

Number $(\%)$ Min-max Mean (SD)

\begin{tabular}{lcc}
\hline Sex & & \\
Male & 54 & \\
Female & 260 & \\
Missing & 9 & \\
Age (years) & $18-40$ & $21.2(2.58)$ \\
BMI & $15.9-37.2$ & $21.9(3.2)$ \\
Underweight $(\mathrm{BMI} \leq 18.49)$ & $30(9.3 \%)$ & \\
Normal weight & $235(72.8 \%)$ \\
$\quad($ BMI 18.5-24.99) & $57(17.9 \%)$ \\
Overweight or obese & & \\
$\quad($ BMI $\geq 25)$ & $33(10.2 \%)$
\end{tabular}

$B M I$ body mass index based on self-reported weight and height

Meditation practice was measured with a single question asking the participants if they meditate regularly, at least once a week

Obesity status was assessed using the BMI calculated from self-reported weight and height. We followed the guideline of the WHO to categorize the BMI values (2018). Two groups were formed for the purposes of statistical analysis: underweight $(\mathrm{BMI} \leq 18.4)$ or normal weight (BMI 18.5-24.9) and overweight $(\mathrm{BMI} \geq 25)$ or obese $(\mathrm{BMI} \geq 30)$.

Meditation practice was measured with one item asking the participants if they meditate regularly, at least once per week, which also might include practicing meditation at a yoga class.

\section{Data Analysis}

We used MPlus 7.4 and SPSS 20.0 statistical software to process the analyses. Confirmatory factor analysis (CFA) was used to examine the original factor structure of the MEQ. This enabled us to test the validity of the a priori model. To see if the original factor structure fit the dataset of the current study, we used a version of maximum likelihood method of estimation that is robust to deviation from normal distribution (MLR) (Brown and Moore 2012; Muthén and Muthén 19982017). The values of several fit indices, namely the chi-square statistic, comparative-fit-index (CFI), Tucker-Lewis index (TLI), and root mean square error of approximation (RMSEA) were evaluated as a part of the data analysis. A satisfactory degree of fit requires the CFI and TLI to be greater than 0.95. An RMSEA below 0.05 indicates excellent fit; a value around 0.08 indicates adequate fit, and a value greater than 0.10 indicates poor fit. We also applied the standardized root mean square residual (SRMR). Here, a good fit is reflected by values less than 0.08 . The outcome of the CFA made it necessary to also apply exploratory factor analysis (EFA). The exploration of the Hungarian version of the MEQ was done using principal axis factoring (PAF) and an oblique (direct oblimin) method of rotation, as correlations between the different factors of mindful eating were expected. We used factor scores resulting from the EFA in subsequent statistical procedures involving the MEQ subscales. Cronbach's alpha coefficients were calculated and evaluated to test the internal consistency of the tool's subscales. Next, we applied principal component analysis (PCA) to uncover the latent structure of the subscales.

The in-between relations of the MEQ subscales and the relationship between the subscales and their validating constructs were explored with the help of correlation coefficients. Kruskal-Wallis analysis with post hoc-adjusted significance testing was applied to understand whether there is a difference in the scores reached on the subscales by the different BMI groups (underweight/normal weight and overweight/obese). We then ran a multivariate regression analysis with structural equation modeling (SEM) to test the predictive power of the validating constructs over the subscales of the MEQ.

\section{Results}

\section{Confirmatory Factor Analyses}

We used CFA to examine the degree of fit of the original measurement model to the current data, expecting the original model to be replicated. However, the CFA yielded unsatisfactory fit indices $\left(\chi^{2}=700.0, d f=340, p<0.001 ; \mathrm{CFI}=0.832\right.$; $\mathrm{TLI}=0.813 ;$ RMSEA $=0.057$ [0.051-0.063]; SRMR = 0.037). We examined the factor loadings and found that one item ("I eat so quickly that I don't taste what I'm eating") did not load significantly onto the distraction factor. Therefore, we repeated the analysis excluding this item, but the degree of fit improved only slightly $\left(\chi^{2}=608.6, d f=314, p<0.001\right.$; $\mathrm{CFI}=0.858 ; \mathrm{TLI}=0.842 ; \mathrm{RMSEA}=0.054$ [0.047-0.060]; SRMR $=0.068$ ). With an inspection of modification indices, we freed two error covariance between items ("When a restaurant portion is too large, I stop eating when I'm full" and "When I'm at a restaurant, I can tell when the portion I've been served is too large for me," both items belonging to the disinhibition subscale; as well as "I have trouble not eating ice cream, cookies, or chips if they're around the house" and "I snack without noticing that I am eating," items of the emotional response subscale), which resulted in a somewhat improved degree of fit $\left(\chi^{2}=548.0, d f=312, p<0.001\right.$; CFI $=$ $0.886 ;$ TLI $=0.872 ;$ RMSEA $=0.048$ [0.042-0.055]; SRMR =0.066). Although the RMSEA and SRMR showed an excellent degree of fit, the CFI and TLI remained in the unacceptable value range. Thus, our analysis did not confirm the original measurement model. Overall, these results cast doubt as to whether the original factor structure would be an appropriate representation of the latent factor structure of the 
data obtained in this study. Therefore, we applied EFA as a next step.

\section{Exploratory Factor Analyses}

We performed EFA with oblique rotation to understand the latent factor structure of the Hungarian version of the MEQ. All 28 items were entered into the process of principal axis factoring. Because the differing fit indices of the CFA yielded mixed results, we limited the number of factors to five to understand if a five-factor solution of the EFA brings about considerable changes in the factor structure. This decision is supported by an examination of the eigenvalues and the scree plot showing an inflection point at factors 4 and 5 . The five factors explained $48.6 \%$ of the total variance. The original five factors were replicated with only minor deviations. One item ("I notice when foods and drinks are too sweet") did not load meaningfully on any of the factors and therefore was excluded from the following analyses. The following item: "I eat so quickly that I don't taste what I'm eating" loaded on the awareness subscale instead of its original distraction factor in the resulting model. The five subscales, the factor loadings of the items, the descriptive statistical data of each factor, and Cronbach's alpha coefficients are presented in Table 2.

\section{Correlations Between Mindful Eating Factors and Their PCA}

To establish the degree of convergent validity, we tested intercorrelations between the subscales of the MEQ, applying correlational analyses. The correlation coefficients were calculated using the slightly modified subscales, suggested by the results of the EFA. The range of correlations between factors was between -0.36 and 0.52 (see Table 3 ). We expected the subscales of the MEQ to show significant and positive associations with each other, which would imply the coherence of the measure and the underlying construct. Some of the results contradicted this expectation. First, Disinhibition did not correlate with Awareness and External Cues. Second, Awareness did not correlate with Distraction. On the contrary, it showed a weak but significant inverse correlation with Emotional Response. That is, the more awareness someone exhibits toward eating-related stimuli and the internal states evoked by these stimuli, the more likely one is to start eating in response to negative internal states. It is important to note that only Awareness had a significant positive correlation with External Cues. The latter subscale correlated significantly and inversely with both Emotional Response and Distraction.

To understand the pattern of correlations of the five factors, we performed a PCA with oblimin rotation and uncovered two main components of the subscales, which explained $64 \%$ of the variance. The factor loadings are presented in Table 3. Disinhibition, Emotional Response, and Distraction showed cohesion and thus were grouped into the first component, which we called self-regulation. The other component includes Awareness and External Cues, which we labeled Awareness. It is salient that the two higher-order components are in an inverse relationship $(r=-0.17, p=0.002)$. This means that the more one can be characterized with selfregulation when it comes to eating, the less mindful one is concerning External Cues and Awareness, and vice versa; nevertheless, the association is weak. Because the five subscales together did not seem to indicate unity, we decided not to use the composite MEQ score in subsequent analyses of the questionnaire, but rather, we examined the properties of each subscale and the two principal components individually. A detailed description of this analysis is available from the authors.

\section{The Relationship Between the Facets of Mindful Eating and Their Validating Constructs}

As far as the validating constructs are concerned, both the correlation analysis and the multivariate regression analysis with SEM provided mixed results. We assumed a significant negative association between the MEQ factor scores and BMI. Two of the five factors of the MEQ showed a rather weak correlation with obesity status in the expected direction (see Table 3). We also suggested that the subscales of MEQ would differentiate between the BMI groups. The comparisons of the three BMI groups revealed a significant difference only in the External Cues subscale $(H(2)=8.70, p=.013)$. The post hoc analysis unveiled a significant difference between the normal weight and the overweight/obese groups, the former scoring higher on the subscale in question $(B=39.65, p<0.05$, effect size $r=0.16$, means 3.22 and 2.94, respectively). This difference was prevalent in the principal component of awareness as well $(H(2)=9.19, p=0.010$; post hoc analysis $B=41.08$, $p<0.05$, effect size $r=0.17$ ). The correlation coefficients describing the relationship between MEQ subscales and the validating factors, namely mindfulness, impulsiveness, emotional eating, uncontrolled eating, and meditation practice, are shown in Table 3. Even though mindfulness was presumed to be positively related to the awareness subscale, it did not show a significant correlation with the MAAS's mindfulness facet. Confirming the hypothesis, disinhibition was inversely and significantly related to uncontrolled eating as measured by TFEQ-R21. The pattern is similar between emotional eating and emotional response, as expected, only with a larger correlation coefficient. Regarding impulsiveness, the assumed negative association with the External Cues subscale could not be confirmed because this factor of mindful eating was found to be unrelated to the validating construct. A significant negative correlation with emotional eating could have also verified the construct validity of External Cues, but their association was significantly positive. This means that those 


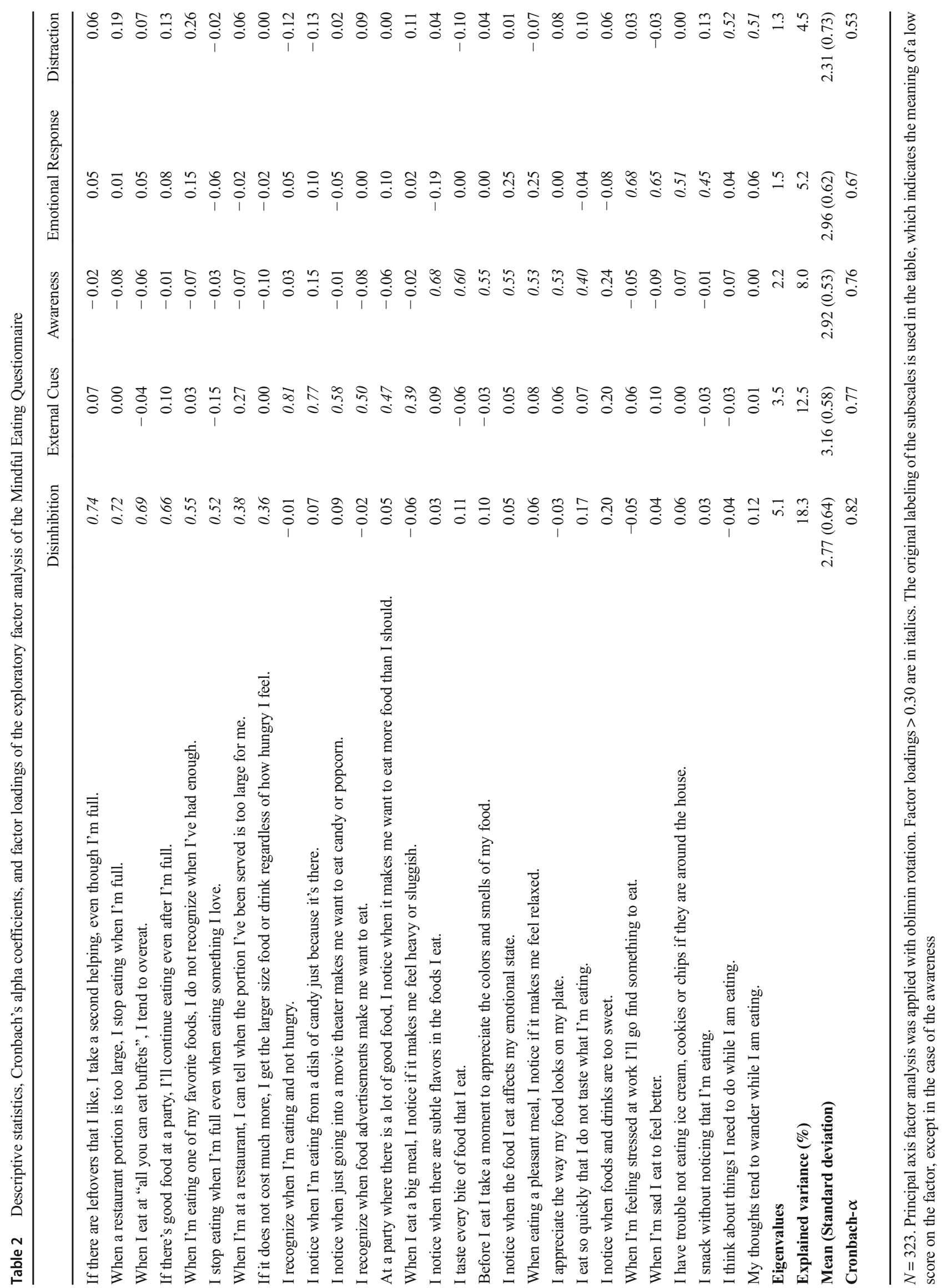


Table 3 Summary of intercorrelations for the Mindful Eating Questionnaire's subscales, the validating constructs and the principal components

\begin{tabular}{|c|c|c|c|c|c|c|c|}
\hline & 1 & 2 & 3 & 4 & 5 & Self-regulation ${ }^{\mathrm{a}}$ & Awareness ${ }^{\mathrm{b}}$ \\
\hline & \multicolumn{5}{|c|}{ Correlations between factors } & \multicolumn{2}{|c|}{ Factor loadings of PCA } \\
\hline 1. Disinhibition & - & - & - & - & - & $0.80^{\mathrm{c}}$ & $0.17^{\mathrm{c}}$ \\
\hline 2. External Cues & -0.02 & - & - & - & - & $-0.31^{\mathrm{c}}$ & $0.80^{\mathrm{c}}$ \\
\hline 3. Awareness & 0.02 & 0.32 & - & - & - & $-0.05^{\mathrm{c}}$ & $0.79^{\mathrm{c}}$ \\
\hline 4. Emotional Response & 0.52 & -0.36 & -0.21 & - & - & $0.85^{\mathrm{c}}$ & $-0.35^{\mathrm{c}}$ \\
\hline 5. Distraction & 0.20 & -0.25 & -0.05 & 0.37 & - & $0.61^{\mathrm{c}}$ & $-0.27^{\mathrm{c}}$ \\
\hline \multicolumn{8}{|c|}{ Correlations between the subscales of the Mindful Eating Questionnaire and the validating constructs } \\
\hline Obesity status & -0.05 & -0.18 & -0.12 & -0.01 & -0.06 & -0.04 & -0.17 \\
\hline Meditation practice & -0.05 & 0.10 & 0.07 & -0.02 & -0.10 & -0.06 & 0.08 \\
\hline Mindfulness (MAAS-H) & 0.24 & -0.10 & 0.02 & 0.31 & 0.20 & 0.31 & -0.03 \\
\hline Impulsiveness (BIS-11) & -0.27 & -0.02 & -0.04 & -0.16 & -0.11 & -0.28 & -0.05 \\
\hline Uncontrolled Eating (TFEQ-R21) & -0.61 & 0.13 & 0.18 & -0.45 & -0.21 & -0.65 & 0.19 \\
\hline Cognitive Restrain (TFEQ-R21) & 0.14 & 0.08 & 0.10 & 0.00 & -0.01 & 0.10 & 0.10 \\
\hline Emotional Eating(TFEQ-R21) & -0.33 & 0.22 & 0.18 & -0.71 & -0.20 & -0.54 & 0.22 \\
\hline
\end{tabular}

$N=314-323$. Pearson's correlations. The factor scores of the subscales of MEQ were used in the estimation of correlations. The original labeling of the subscales is used in the table, which indicates the meaning of a low score on the factor, except in the case of the Awareness. Obesity status is coded as 0 normal or underweight, 1 overweight or obese. Meditation practice is coded as 0 no regular, weekly meditation, 1 meditation practice at least once a week. PCA Principal Component Analysis; MAAS-H Mindful Awareness and Attention Scale-Hungarian version; BIS-11 Barratt Impulsiveness Scale; TFEQ-R21 Three Factor Eating Questionnaire

${ }^{a}$ Self-regulation is a composite score of Disinhibition, Emotional Response, and Distraction. ${ }^{\mathrm{b}}$ Awareness is a composite score of Awareness and External Cues factors. ${ }^{\mathrm{c}}$ Factor loadings of PCA

Italicized coefficients are significant at least at $p<0.05$

individuals who are more mindful and recognize when external cues elicit eating behavior also exhibit a tendency to respond to strong or uncomfortable emotions by eating, contradicting our a priori hypotheses. Unlike this previous result, the subscales of Emotional Response and Disinhibition were related to impulsiveness in the presumed positive direction. However, inconsistent with the result of the correlation analysis, the scores attained on the impulsiveness scale do not seem to have a significant predictive power over the scores of the Disinhibition factor when included in the multivariate regression analysis (Table 4). Studies involving the general population found mixed results concerning changes in cognitive restraint after mindfulness-based eating interventions (Alberts et al. 2012; Dalen et al. 2010). Therefore, we wished to explore the relationship of these eating behaviors. Cognitive restraint in eating habits revealed no relationship with four out of the five factors and indicated a significant but small and positive correlation with the disinhibition factor (see Table 3). In the multivariate regression model, cognitive restraint had modest predictive power over the Emotional Response subscale (Table 4). Finally, even though the correlation analysis indicates no relationship between regular meditation practice and the MEQ subscales contrary to our expectations (Table 3), the result of the multivariate regression analysis pointed out small, but significant and negative beta values in the case of Distraction and Disinhibition. This latter finding was present in the case of Self-regulation as well (Table 4).
The rest of the beta values resulting from the multivariate regression analysis with SEM (Table 4) are in line with what the correlation coefficients revealed. The results of the multivariate regression analysis in the case of the two principal components show the same trend as the betas of the relating subscales and their validating factors (see Table 4). It might be of interest to highlight that Self-regulation but not Awareness was significantly and positively predicted by mindfulness, although the Awareness subscale is part of the latter component.

\section{Discussion}

This study explored the construct validity of mindful eating by placing it in a nomological net of similar constructs and by testing the psychometric properties of the Hungarian version of the MEQ. Although the results of the CFA did not assure an adequate fit to the original model structure, applying an EFA provided us with a 5 -factor model that was nearly identical to the original one. The one item loading on a different factor than in the original structure indeed shares commonalities in its content with its new Awareness factor, as it describes a lack of awareness of the act of tasting the food. However, this left the Distraction factor with only two items loading onto it that poses limitations to the interpretation of the results including this subscale. Further analysis revealed that the five subscales 
Table 4 Results of multivariate regression analysis for predicting the factors of the MEQ and their principal components

\begin{tabular}{lccccccc}
\hline & \multicolumn{2}{l}{ Outcome variables } & & & \\
\cline { 2 - 7 } Predictors & Disinhibition & External Cues & Awareness & Emotional Response & Distraction $^{\text {Self-regulation }}{ }^{\mathrm{a}}$ & Awareness $^{\mathrm{b}}$ \\
\hline Obesity status & -0.03 & -0.19 & -0.15 & 0.03 & -0.05 & -0.02 & -0.20 \\
Meditation practice & -0.08 & 0.10 & 0.08 & -0.06 & -0.14 & -0.12 & 0.11 \\
Mindfulness (MAAS-H) & 0.06 & -0.09 & 0.11 & 0.11 & 0.10 & 0.13 & 0.01 \\
Impulsiveness (BIS-11) & -0.03 & -0.10 & -0.04 & 0.03 & -0.03 & -0.01 & -0.08 \\
Uncontrolled Eating (TFEQ-R21) & -0.54 & 0.09 & 0.16 & -0.21 & -0.20 & -0.43 & .0 .06 \\
Cognitive Restrain (TFEQ-R21) & 0.01 & -0.02 & 0.05 & 0.08 & 0.03 & 0.05 & 0.03 \\
Emotional Eating (TFEQ-R21) & -0.10 & 0.16 & 0.07 & -0.65 & -0.13 & -0.40 & 0.20 \\
$\boldsymbol{R}^{2}$ & $40.8 \%$ & $16.4 \%$ & $10.1 \%$ & $62.9 \%$ & $17.3 \%$ & $56.2 \%$ & $18.9 \%$ \\
\hline
\end{tabular}

$N=300$. Standardized regression coefficients. Outcome variables are factor scores as observed variables. The original labeling of the subscales is used in the table, which indicates the meaning of a low score on the factor, except in the case of the Awareness. Results are controlled for the effects of age and sex. Obesity status is coded as 0: normal or underweight, 1: overweight or obese. Meditation practice is coded as 0: no regular, weekly meditation, 1: meditation practice at least once a week. MAAS-H = Mindful Awareness and Attention Scale - Hungarian version; BIS-11 = Barratt Impulsiveness Scale; TFEQ-R21 = Three Factor Eating Questionnaire

${ }^{a}$ Self-regulation is a composite score of Disinhibition, Emotional Response, and Distraction. ${ }^{\mathrm{b}}$ Awareness is a composite score of Awareness and External Cues factors

Boldfaced coefficients are significant at least at $p<.05$

represent two different and weakly correlating components, namely Self-regulation and Awareness. The former component encompasses the Disinhibition, Emotional Response, and Distraction factors, and the latter covers the External Cues and the Awareness subscales. Clementi et al. (2017) used a different methodology to test the reliability and validity of the Italian version of the MEQ by first defining the number of items to keep based on content validity indices assigned to the items by experts and then analyzing the questionnaire by means of EFA and CFA. Regardless of the selected route of psychometric analysis, their research yielded a two-factor solution in which the grouping of the items compares to the composition of the principal components produced by our study (the Awareness and External Cues items belonging to a factor called awareness, and mostly the items from the Disinhibition subscale making up the recognition factor). Similarly, a two-factor structure emerged from the study of the children version of the MEQ by Hart et al. (2018), where the two factors showed very weak correlation $(r=0.02)$, which is congruent with our findings. The awareness factor detected in the latter study covered four items originating from the awareness factor, and the mindless eating factor included items from the Disinhibition (three items), External Cues (one item), Emotional Response (three items), and Distraction (one item) factors. Comparable to our finding, other studies testing the psychometric properties of the MEQ also found little cohesion between the five subscales (Abbaspoor et al. 2018; Apolzan et al. 2016). Moreover, the principal components of awareness and self-regulation exhibited weak and negative associations in our study, reinforcing the lack of concordance between the elements of mindful eating.
A possible explanation for the negative relationship of External Cues with both the Distraction and Emotional Response factors might be that people who tend to eat in response to difficult emotional states or get distracted by thoughts while eating may already have identified these behaviors as problematic and thus consciously attempt to better control and monitor the food environment they are in to avoid overeating. This might be in line with studies suggesting that people who tend to restrict their eating behavior are also the ones who tend to binge eat when conditions change and the efforts to restrain oneself from eating cannot be sustained (Ward and Mann 2000). These results, and those suggesting that individuals scoring higher on the Awareness component can be described with lower levels of Self-regulation, might be due to the fact that while acceptance is an inherent component of mindfulness, this questionnaire fails to measure it. It might be possible that there are individuals who pay attention to their meals and the emotions and sensations evoked by food but who cannot accept the persistence of uncomfortable or salient internal states in the food environment. Thus, these people would opt for managing discomfort by eating. As an alternative explanation, it might also be possible that the items of the awareness factor might describe a different type of conscious attention than what plays a role in the commencement and termination of eating behavior that is incorporated in the Disinhibition subscale. Investigating construct validity also suggested that the Awareness factor in the MEQ incorporates a somewhat different approach than what the concept of mindfulness implies in general, for there was a lack of correlation between these two constructs. While in the case of the MEQ, eating-related Awareness focuses on the impact that food has 
on internal states and sensations, the general meaning of mindfulness emphasizes awareness in a much broader sense, as the ability to observe the internal and external reality and experiences of the present moment as a whole (and their components) (Brown and Ryan 2003). Our result suggesting the separation of different aspects of awareness when it comes to eating behavior is supported by a study that identified two different types of awareness factors concerning eating, distinguishing paying attention to sensory and bodily experiences from acting with awareness (Hulbert-Williams et al. 2014).

We gained mixed results regarding the associations of the other MEQ subscales and their validating variables. Although the Disinhibition and the Emotional Response factors indicated appropriate convergent validity using uncontrolled eating and impulsiveness as validating variables, the External Cues subscale did not show associations with its validating constructs, as in the case of Awareness. On the component level, Self-regulation associated positively with general mindfulness and inversely with uncontrolled eating and emotional eating. This finding suggests that self-regulation might have a shielding role against the loss of control over eating. The principal component of awareness was associated with obesity status as expected, reflecting that overweight or obese respondents were less likely to endorse the awareness component of mindful eating, although the strength of this association was weak. Regarding the different BMI groups, only the External Cues subscale was able to differentiate between normal weight and overweight/obese individuals, with normal weight people being more mindful in a food-related environment. Interestingly, practicing meditation was not associated with mindful eating, although the simple question inquiring about regular meditation practice did not specify the type and intensity of meditation practice.

Our study has contributed to progress in the measurement of mindful eating highlighting the strengths and weaknesses of using the MEQ. Our study is in accordance with previous research that pointed out the difficulties with confirming the originally hypothesized factor structure of the MEQ. However, in our study, the structure of the MEQ only slightly differed from that of the originally proposed one. We can conclude that the relationship of the validating variables and mindful eating is rather elusive. There has been only a limited scientific endeavor that would aim to define the place of mindful eating in a nomological network and to clarify its conceptualization. Our study distinguished the Self-regulation and Awareness components of one of the most frequently used measures of mindful eating. Framson et al. (2009) focused their definition on the bodily and emotional experiences evoked by eating or eating-related events. Including items that would describe hunger, or reactions to it, and adding a nonjudgmental approach and an emphasis on the acceptance aspect of the mindful eating experience could further improve the content validity of this scale. For this reason, it would be worth inspecting the psychometric properties of a more recent measure of mindful eating, the Mindful Eating Scale too, that covers a broader spectrum of facets associated to the construct of mindfulness (Hulbert-Williams et al. 2014).

\section{Limitations and Future Research}

The cross-sectional survey design applied in this study did not enable us to draw conclusions on causality in the relationship of the measured variables. The generalizability of the results is limited due to the convenience sampling and the homogeneity of the sample, as only university students filled out the questionnaires. Other limitations of this study include using BMI values calculated based on self-reported data rather than objective measurements and using a measure of meditation practice that was not refined enough to differentiate between different groups of meditators. Additional research needs to test exactly how mindful eating and self-regulation relate to each other. We believe that clarifying the construct and its operationalization can take place simultaneously. It is beyond the scope of the current study to draw a conclusion about whether the slight divergence between the Hungarian and the original factor structure of the MEQ is due to cultural, linguistic, or translational reasons, or if it is due to the specificities of the construct of mindful eating measured by the MEQ. Nevertheless, cultural differences might play a significant role in research addressing eating behaviors.

Having a reliable and valid questionnaire measuring mindful eating can help us to define more successful weight loss strategies that can be tailored to the needs of individuals and that deal not only with what and when they eat but also why and how they eat. In the future, aside from continued research on the conceptualization and operationalization of mindful eating, it would be interesting to compare the measurement of mindful eating with information about the daily nutrition and eating habits of participants by applying experience sampling methods. This would enable further and more thorough validation of the construct. Placing a more pronounced emphasis on the examination of desirable eating habits could also promote building a healthier relationship to food and eating and to combat disordered eating behaviors by applying a novel approach.

Acknowledgments We are grateful for Zsuzsa Londe for her help in proofreading the article and for Linda Vadász and Justin Tőkés for finetuning the Hungarian version of the questionnaire.

Author Contributions Both authors participated equally in designing and executing the study, including data analyses and writing the paper. Data collection was conducted by NR. Both authors approved the final version of the manuscript for submission. 
Funding Information Open access funding provided by Eötvös Loránd University (ELTE). This work was completed within the framework of ELTE. Institutional Excellence Program (783-3/2018/FEKUTSRAT) supported by the Hungarian Ministry of Human Capacities.

\section{Compliance with Ethical Standards}

Conflict of Interest The authors declare that they have no conflict of interest.

Ethical Approval The manuscript does not contain clinical studies or patient data. The study protocol was approved by the Ethical Committee of Eötvös Loránd University (Budapest, Hungary).

Informed Consent Informed consent was obtained from all individual participants included in the study.

Open Access This article is distributed under the terms of the Creative Commons Attribution 4.0 International License (http:// creativecommons.org/licenses/by/4.0/), which permits unrestricted use, distribution, and reproduction in any medium, provided you give appropriate credit to the original author(s) and the source, provide a link to the Creative Commons license, and indicate if changes were made.

\section{References}

Abbaspoor, Z., Javadifar, N., Miryan, M., \& Abedi, P. (2018). Psychometric properties of the Iranian version of mindful eating questionnaire in women who seeking weight reduction. Journal of Eating Disorders, 6(1), 33-40. https://doi.org/10.1186/s40337-0180220-4.

Alberts, H. J. E. M., Thewissen, R., \& Raes, L. (2012). Dealing with problematic eating behaviour. The effects of a mindfulness-based intervention on eating behaviour, food cravings, dichotomous thinking and body image concern. Appetite, 58(3), 847-851. https://doi. org/10.1016/j.appet.2012.01.009.

Allirot, X., Miragall, M., Perdices, I., Baños, R. M., Urdaneta, E., \& Cebolla, A. (2017). Effects of a brief mindful eating induction on food choices and energy intake: external eating and mindfulness state as moderators. Mindfulness, 9(3), 750-760. https://doi.org/10. 1007/s12671-017-0812-0.

Apolzan, J. W., Myers, C. A., Cowley, A. D., Brady, H., Hsia, D. S., Stewart, T. M., et al. (2016). Examination of the reliability and validity of the mindful eating questionnaire in pregnant women. Appetite, 100, 142-151. https://doi.org/10.1016/j.appet.2016.02. 025 .

Borsa, J. C., Damásio, B. F., \& Bandeira, D. R. (2012). Cross-cultural adaptation and validation of psychological instruments: some considerations. Paidéia (Ribeirão Preto), 22(53), 423-432. https://doi. org/10.1590/1982-43272253201314.

Brown, T. A., \& Moore, M. T. (2012). Confirmatory factor analysis. In R. H. Hoyle (Ed.), Handbook of structural equation modeling (pp. 361-379). New York London: The Guilford press.

Brown, K. W., \& Ryan, R. M. (2003). The benefits of being present: mindfulness and its role in psychological well-being. Journal of Personality and Social Psychology, 84(4), 822-848. https://doi. org/10.1037/0022-3514.84.4.822.

Brown, K. W., Ryan, R. M., \& Creswell, J. D. (2007). Mindfulness: theoretical foundations and evidence for its salutary effects. Psychological Inquiry, 18(4), 211-237. https://doi.org/10.1080/ 10478400701598298.
Caldwell, K., Baime, M., \& Wolever, R. (2012). Mindfulness based approaches to obesity and weight loss maintenance. Journal of Mental Health Counseling, 34(3), 269-282. https://doi.org/10.17744/mehc. 34.3.t016616717774643.

Camilleri, G. M., Méjean, C., Bellisle, F., Hercberg, S., \& Péneau, S. (2015). Association between mindfulness and weight status in a general population from the NutriNet-Santé study. PLoS One, 10(6), e0127447. https://doi.org/10.1371/journal.pone.0127447.

Carrière, K., Khoury, B., Günak, M. M., \& Knäuper, B. (2018). Mindfulness-based interventions for weight loss: a systematic review and meta-analysis: mindfulness interventions for weight loss. Obesity Reviews, 19(2), 164-177. https://doi.org/10.1111/obr. 12623.

Clementi, C., Casu, G., \& Gremigni, P. (2017). An abbreviated version of the mindful eating questionnaire. Journal of Nutrition Education and Behavior, 49(4), 352-356. https://doi.org/10.1016/j.jneb.2017. 01.016 .

Cooper, Z., Doll, H. A., Hawker, D. M., Byrne, S., Bonner, G., Eeley, E., et al. (2010). Testing a new cognitive behavioural treatment for obesity: a randomized controlled trial with three-year follow-up. Behaviour Research and Therapy, 48(8), 706-713. https://doi.org/ 10.1016/j.brat.2010.03.008.

Czeglédi, E., \& Urbán, R. (2010). A háromfaktoros evési kérdőív (threefactor eating questionnaire revised 21-item) hazai adaptációja. Magyar Pszichológiai Szemle, 65(3), 463-494. https://doi.org/10. 1556/MPSzle.65.2010.3.2.

Dalen, J., Smith, B. W., Shelley, B. M., Sloan, A. L., Leahigh, L., \& Begay, D. (2010). Pilot study: mindful eating and living (MEAL): weight, eating behavior, and psychological outcomes associated with a mindfulness-based intervention for people with obesity. Complementary Therapies in Medicine, 18(6), 260-264. https:// doi.org/10.1016/j.ctim.2010.09.008.

Elliston, K. G., Ferguson, S. G., Schüz, N., \& Schüz, B. (2017). Situational cues and momentary food environment predict everyday eating behavior in adults with overweight and obesity. Health Psychology, 36(4), 337-345. https://doi.org/10.1037/hea0000439.

Framson, C., Kristal, A. R., Schenk, J. M., Littman, A. J., Zeliadt, S., \& Benitez, D. (2009). Development and validation of the mindful eating questionnaire. Journal of the American Dietetic Association, 109(8), 1439-1444. https://doi.org/10.1016/j.jada.2009.05.006.

Gilbert, D., \& Waltz, J. (2010). Mindfulness and health behaviors. Mindfulness, 1(4), 227-234. https://doi.org/10.1007/s12671-0100032-3.

Gregoire, J. (2018). ITC guidelines for translating and adapting tests. $J$ Test, 18(2), 101-134. https://doi.org/10.1080/15305058.2017. 1398166.

Hart, J. (2014). Healthy behaviors linked to practice of mindful eating. Alternative and Complementary Therapies, 20(6), 317-319. https:// doi.org/10.1089/act.2014.20605.

Hart, S. R., Pierson, S., Goto, K., \& Giampaoli, J. (2018). Development and initial validation evidence for a mindful eating questionnaire for children. Appetite, 129, 178-185. https://doi.org/10.1016/j.appet. 2018.07.010.

Hendrickson, K. L., \& Rasmussen, E. B. (2013). Effects of mindful eating training on delay and probability discounting for food and money in obese and healthy-weight individuals. Behaviour Research and Therapy, 51(7), 399-409. https://doi.org/10.1016/j. brat.2013.04.002.

Hendrickson, K. L., \& Rasmussen, E. B. (2017). Mindful eating reduces impulsive food choice in adolescents and adults. Health Psychology, 36(3), 226-235. https://doi.org/10.1037/hea0000440.

Hruby, A., \& Hu, F. B. (2015). The epidemiology of obesity: A big picture. PharmacoEconomics, 33(7), 673-689. https://doi.org/10. 1007/s40273-014-0243-x. 
Hulbert-Williams, L., Nicholls, W., Joy, J., \& Hulbert-Williams, N. (2014). Initial validation of the mindful eating scale. Mindfulness, 5(6), 719-729. https://doi.org/10.1007/s12671-013-0227-5.

Jordan, C. H., Wang, W., Donatoni, L., \& Meier, B. P. (2014). Mindful eating: trait and state mindfulness predict healthier eating behavior. Personality and Individual Differences, 68, 107-111. https://doi.org/ 10.1016/j.paid.2014.04.013.

Kremers, S. P. J., de Bruijn, G.-J., Visscher, T. L. S., van Mechelen, W., de Vries, N. K., \& Brug, J. (2006). Environmental influences on energy balance-related behaviors: a dual-process view. The International Journal of Behavioral Nutrition and Physical Activity, 3, 9. https:// doi.org/10.1186/1479-5868-3-9.

Mathieu, J. (2009). What should you know about mindful and intuitive eating? Journal of the American Dietetic Association, 109(12), 1982-1987. https://doi.org/10.1016/j.jada.2009.10.023.

Monroe, J. T. (2015). Mindful eating: Principles and practice. American Journal of Lifestyle Medicine, 9(3), 217-220. https://doi.org/10. $1177 / 1559827615569682$.

Moor, K. R., Scott, A. J., \& McIntosh, W. D. (2013). Mindful eating and its relationship to body mass index and physical activity among university students. Mindfulness, 4(3), 269-274. https://doi.org/10. 1007/s12671-012-0124-3.

Muthén, L. K., \& Muthén, B. O. (1998-2017). MPlus User's Guide (8th ed.). Los Angeles, CA: Muthén \& Muthén.

Niemeier, H. M., Leahey, T., Palm Reed, K., Brown, R. A., \& Wing, R. R. (2012). An acceptance-based behavioral intervention for weight loss: a pilot study. Behavior Therapy, 43(2), 427-435. https://doi. org/10.1016/j.beth.2011.10.005.

O'Reilly, G. A., Cook, L., Spruijt-Metz, D., \& Black, D. S. (2014). Mindfulness-based interventions for obesity-related eating behaviours: a literature review: mindfulness interventions for eating behaviours. Obesity Reviews, 15(6), 453-461. https://doi.org/10.1111/ obr.12156.

OECD, \& the European Union. (2014). Health at a Glance: Europe 2014. http://www.oecd-ilibrary.org/social-issues-migration-health/healthat-a-glance-europe-2014_health_glance_eur-2014-en . Accessed 15 Oct 2015.

Papies, E. K., Pronk, T. M., Keesman, M., \& Barsalou, L. W. (2015). The benefits of simply observing: mindful attention modulates the link between motivation and behavior. Journal of Personality and Social Psychology, 108(1), 148-170. https://doi.org/10.1037/a0038032.
Patton, J. H., Stanford, M. S., \& Barratt, E. S. (1995). Factor structure of the Barratt impulsiveness scale. Journal of Clinical Psychology, 51(6), 768-774. https://doi.org/10.1002/1097-4679(199511)51: 6<768::AID-JCLP2270510607>3.0.CO;2-1.

Pidgeon, A., Lacota, K., \& Champion, J. (2013). The moderating effects of mindfulness on psychological distress and emotional eating behaviour: mindfulness and emotional eating behaviours. Australian Psychologist, 48(4), 262-269. https://doi.org/10.1111/j.1742-9544. 2012.00091.x.

Roberts, K. C., \& Danoff-Burg, S. (2010). Mindfulness and health behaviors: is paying attention good for you? Journal of American College Health, 59(3), 165-173. https://doi.org/10.1080/ 07448481.2010 .484452$.

Simor, P., Petke, Z., \& Köteles, F. (2013). Measuring pre-reflexive consciousness: the Hungarian validation of the Mindful Attention Awareness Scale (MAAS). Learning \& Perception, 5(Supplement 2), 17-29.

Stanford, M. S., Mathias, C. W., Dougherty, D. M., Lake, S. L., Anderson, N. E., \& Patton, J. H. (2009). Fifty years of the Barratt impulsiveness scale: an update and review. Personality and Individual Differences, 47(5), 385-395. https://doi.org/10.1016/j. paid.2009.04.008.

Tapper, K., Shaw, C., Ilsley, J., Hill, A. J., Bond, F. W., \& Moore, L. (2009). Exploratory randomised controlled trial of a mindfulnessbased weight loss intervention for women. Appetite, 52(2), 396404. https://doi.org/10.1016/j.appet.2008.11.012.

Walach, H., Buchheld, N., Buttenmüller, V., Kleinknecht, N., \& Schmidt, S. (2006). Measuring mindfulness - the Freiburg mindfulness inventory (FMI). Personality and Individual Differences, 40(8), 1543-1555. https://doi.org/10.1016/j.paid.2005.11.025.

Ward, A., \& Mann, T. (2000). Don't mind if I do: disinhibited eating under cognitive load. Journal of Personality and Social Psychology, 78(4), 753-763. https://doi.org/10.1037//0022-3514. 78.4.753.

World Health Organization. (2018). BMI classification. http://apps.who. int/bmi/index.jsp?introPage=intro_3.html . Accessed 16 Feb 2018.

Publisher's Note Springer Nature remains neutral with regard to jurisdictional claims in published maps and institutional affiliations. 